Article

\title{
Ginsenoside Rb1 Mitigates Escherichia coli Lipopolysaccharide-Induced Endometritis through TLR4-Mediated NF- $k$ B Pathway
}

\author{
Aftab Shaukat ${ }^{1}$, Irfan Shaukat ${ }^{2}$, Shahid Ali Rajput ${ }^{3}$, Rizwan Shukat ${ }^{4}$, Sana Hanif ${ }^{5}$, Imran Shaukat ${ }^{6}$, \\ Xinxin Zhang ${ }^{1}$, Chao Chen ${ }^{1}$, Xuyang Sun ${ }^{1}$, Tingzhu Ye ${ }^{1}$, Kaifeng Niu ${ }^{1}$, Zhiqiu Yao ${ }^{1}$, Shadab Shaukat ${ }^{7}$, \\ Muhammad Safdar ${ }^{1}$, Mohamed Abdelrahman ${ }^{1,8}{ }^{\mathbb{D}}$, Umair Riaz ${ }^{1}$, Junwei Zhao ${ }^{1}$, Xiaoying Gu ${ }^{1}$ \\ and Liguo Yang $1, *$ (1)
}

Citation: Shaukat, A.; Shaukat, I.; Rajput, S.A.; Shukat, R.; Hanif, S.; Shaukat, I.; Zhang, X.; Chen, C.; Sun, X.; Ye, T.; et al. Ginsenoside Rb1 Mitigates Escherichia coli

Lipopolysaccharide-Induced Endometritis through TLR4-Mediated NF-кB Pathway. Molecules 2021, 26, 7089. https://doi.org/10.3390/ molecules26237089

Academic Editors: Raffaele Capasso and Lorenzo Di Cesare Mannelli

Received: 19 October 2021

Accepted: 16 November 2021

Published: 23 November 2021

Publisher's Note: MDPI stays neutral with regard to jurisdictional claims in published maps and institutional affiliations.

Copyright: (C) 2021 by the authors Licensee MDPI, Basel, Switzerland. This article is an open access article distributed under the terms and conditions of the Creative Commons Attribution (CC BY) license (https:/ / creativecommons.org/licenses/by/ $4.0 /)$.
1 National Center for International Research on Animal Genetics, Breeding and Reproduction (NCIRAGBR), Huazhong Agricultural University, Wuhan 430070, China; aftabshaukat40@gmail.com (A.S.); zxx1144795936@163.com (X.Z.); chenchao1995@webmail.hzau.edu.cn (C.C.); sunxuyangabc@163.com (X.S.); yetingzhu@webmail.hzau.edu.cn (T.Y.); nkf_19930806@163.com (K.N.); zhiqiuyao1@163.com (Z.Y.); safdar1126@webmail.hzau.edu.cn (M.S.); Mohamed.Asad@agr.au.edu.eg (M.A.); umair.riaz@iub.edu.pk (U.R.); zjwzjw98@163.com (J.Z.); gxy19970310@163.com (X.G.)

2 Faculty of Medicine, University of Lorraine, 54052 Nancy, France; irfan-uaf@hotmail.com

3 Faculty of Veterinary and Animal Sciences, Muhammad Nawaz Shareef University of Agriculture, Multan 66000, Pakistan; shahid.ali@mnsuam.edu.pk or dr.shahidali@scau.edu.cn

4 Faculty of Food, Nutrition \& Home Sciences, University of Agriculture, Faisalabad 38000, Pakistan; rizwanuaf@hotmail.com

5 Hubei Key Laboratory of Theory and Application of Advanced Materials Mechanics, Wuhan University of Technology, Wuhan 430070, China; Sanahanif96@gmail.com

6 Department of Physics, University of Agriculture, Faisalabad 38000, Pakistan; imran.uaf1349@gmail.com

7 Department of Plant Breeding and Genetics, University of Agriculture, Faisalabad 38000, Pakistan; shadab_uaf@hotmail.com

8 Animal Production Department, Faculty of Agriculture, Assuit University, Asyut 71515, Egypt

* Correspondence: ylg@mail.hzau.edu.cn; Tel.: +86-138-7105-6592

Abstract: Endometritis is the inflammatory response of the endometrial lining of the uterus and is associated with low conception rates, early embryonic mortality, and prolonged inter-calving intervals, and thus poses huge economic losses to the dairy industry worldwide. Ginsenoside $\mathrm{Rb} 1(\mathrm{GnRb} 1)$ is a natural compound obtained from the roots of Panax ginseng, having several pharmacological and biological properties. However, the anti-inflammatory properties of GnRb1 in lipopolysaccharide (LPS)-challenged endometritis through the TLR4-mediated NF- $\mathrm{KB}$ signaling pathway has not yet been researched. This study was planned to evaluate the mechanisms of how GnRb1 rescues LPS-induced endometritis. In the present research, histopathological findings revealed that GnRb1 ameliorated LPS-triggered uterine injury. The ELISA and RT-qPCR assay findings indicated that $\mathrm{GnRb} 1$ suppressed the expression level of pro-inflammatory molecules (TNF$\alpha$, IL-1 $\beta$ and IL-6) and boosted the level of anti-inflammatory (IL-10) cytokine. Furthermore, the molecular study suggested that GnRb1 attenuated TLR4-mediated NF- $\mathrm{KB}$ signaling. The results demonstrated the therapeutic efficacy of GnRb1 in the mouse model of LPS-triggered endometritis via the inhibition of the TLR4-associated NF-kB pathway. Taken together, this study provides a baseline for the protective effect of $\mathrm{GnRb} 1$ to treat endometritis in both humans and animals.

Keywords: endometritis; lipopolysaccharide; Ginsenoside Rb1; TLR4; NF-kB pathway

\section{Introduction}

Endometritis is considered a major global problem and has been associated with a decline in the reproductive performance of animals [1,2]. The postpartum involution period is very crucial regarding the infection of the endometrium caused by bacteria, 
especially Gram-negative (G-ve) bacteria [3]. Among these G-ve bacteria, Escherichia coli (E. coli) is known as the major bacterial etiology of endometritis $[4,5]$. The endometrial lining of the uterus is the first line of defense that recognizes the pathogen-associated molecular pattern (PAMP) from invading pathogens to activate immunity [6]. Toll-like receptor (TLR) 4 is a major PAMP activated by lipopolysaccharide (LPS) [7]. LPS is a potent immune stimulator derived from the outer membrane of G-ve bacteria [8]. Once TLR4 is activated, it triggers the upregulation of underlying inflammatory pathways, especially the NF- $\kappa B$ signaling pathway [5]. Activated TLR4-mediated NF- $\kappa B$ results in the production of pro-inflammatory cytokines that play a role in inflammation $[9,10]$.

Antibiotics are used to treat endometritis globally. However, bacterial resistance and food safety issues are the major concerns to treating endometritis with antibiotics [4]. Therefore, alternative therapeutic agents are in dire need in the current era. Ginsenoside $\mathrm{Rb} 1$ (GnRb1) has well-known anti-inflammatory properties (Figure 1A). GnRb1 was found to suppress Staphylococcus (S.) aureus-triggered inflammatory responses in vivo and in vitro via the TLR2-mediated NF- $\mathrm{kB}$ pathway [11]. In addition, GnRb1 mitigated LPS-caused acute lung injury (ALI) in rats [12]. Intraperitoneal $\mathrm{Rb} 1$ therapy suppresses the levels of the pro-inflammatory markers and attenuates NF- $\mathrm{kB}$ molecules (p-IкB $\alpha$ and $\mathrm{p}-\mathrm{IKK}$ ) in vivo model [13]. In addition, GnRb1 treatment significantly ameliorated LPS-induced microglial inflammation and suppressed the production of pro-inflammatory cytokines [14] Zhu et al. [15] explored the neuroprotective effects of GnRb1 in a rat model of ischemic neuro-inflammation. However, whether GnRb1 has protective effects in LPS-induced endometritis still remains unexplored. Therefore, the present research was planned to explore the beneficial effects of GnRb1 in the murine model of endometritis caused by LPS.

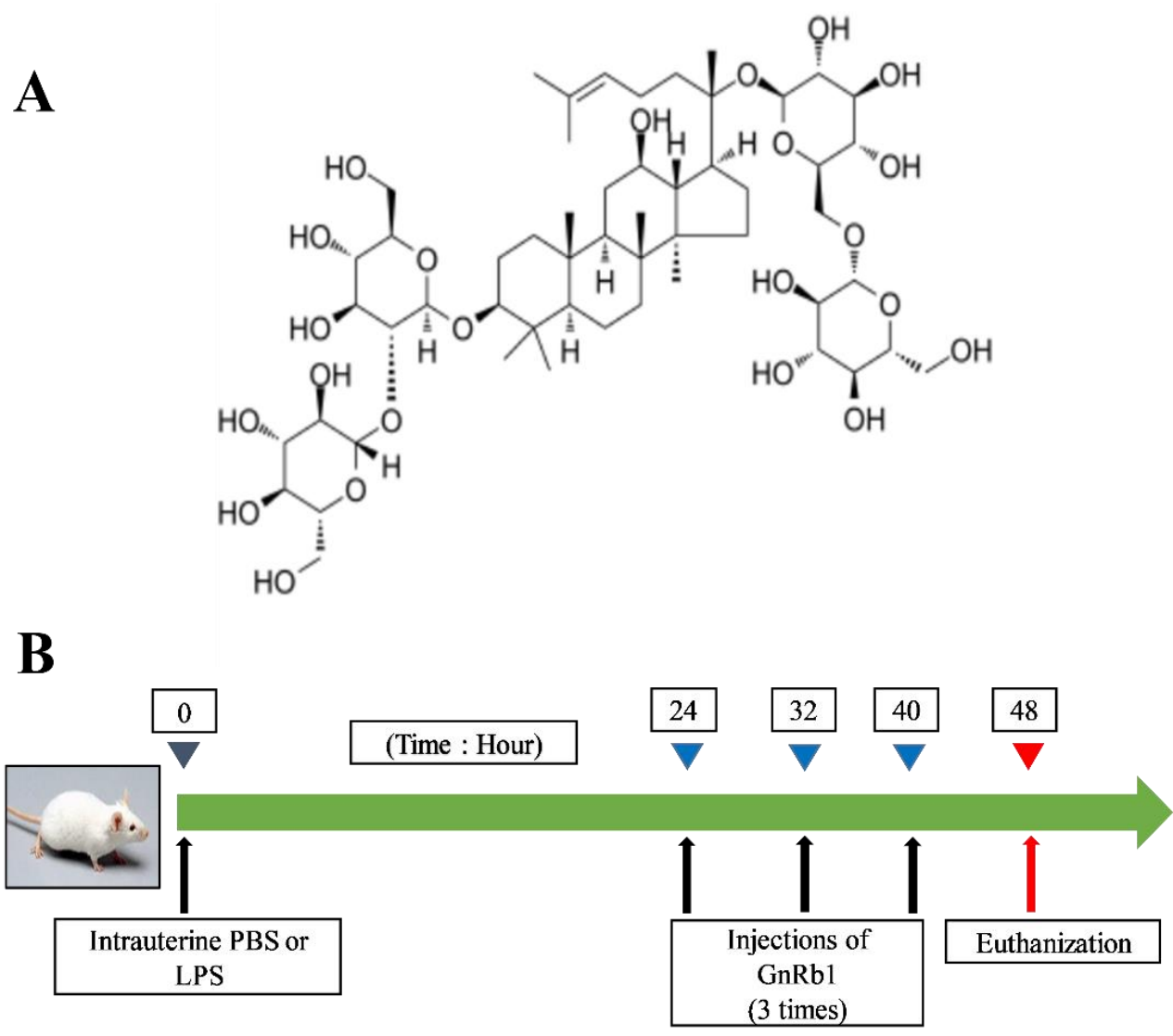

Figure 1. (A) The structure of Ginsenoside Rb1. (B) Animal treatment protocol of this study. 


\section{Materials and Methods}

\subsection{Ethical Approval}

Experiments regarding animals were carried out after being approved by the institutional research ethics and animal welfare committee, Huazhong Agricultural University (HZAUMO_2015-12) (Wuhan, China).

\subsection{Chemicals and Reagents}

GnRb1 was attained from Shanghai Yuanye Bio-Technology Co., Ltd. (Shanghai, China). LPS from E. coli strain (O55:B5) was obtained from Sigma (St. Louis, MO, USA). The ELISA kits to determine MPO, pro- and anti-inflammatory cytokines were obtained from Nanjing Jiancheng Bioengineering Institute (Nanjing, China). ELISA kits NF-kB pathway (total and phospho $\mathrm{I} \kappa \mathrm{B} \alpha$ and NF- $\mathrm{B}$ p 65 ) proteins and primary, and secondary antibodies were procured from Cell Signaling Technology (CST, Danvers, MA, USA).

\subsection{Animal and Experimental Groups}

Sixty female BALB/c mice of $25 \pm 2 \mathrm{~g}$ weight were procured from Wuhan University (Wuhan, China). The mice were arbitrarily divided into four $(n=15)$ groups as follows:

1. Control group (50 $\mu \mathrm{L}$ of Saline solution);

2. LPS group (a volume of $50 \mu \mathrm{L}$ having a concentration of $1 \mathrm{mg} / \mathrm{mL}$ );

3. LPS + GnRb1 (25 mg/kg) group;

4. $\mathrm{LPS}+\mathrm{GnRb1}(50 \mathrm{mg} / \mathrm{kg})$ group.

LPS-induced endometritis was established by intrauterine infusion of $50 \mu \mathrm{L}$ of LPS $(1 \mathrm{mg} / \mathrm{mL})$ according to the previous study [4,7]. After $24 \mathrm{~h}$, mice were injected intraperitoneally with $\mathrm{GnRb} 1$ ( 25 and $50 \mathrm{mg} / \mathrm{kg}$ ) thrice, $8 \mathrm{~h}$ apart. Eight hours after the last GnRb1 injection, mice were euthanized to collect uterine samples. The animal treatment protocol of this study is displayed in (Figure 1B).

\subsection{Histological Assay}

The uterine tissue sections were placed in a $10 \%$ formalin solution for 2 days for tissue fixation purposes. These sections were then dehydrated and embedded in liquid paraffin. The samples were dewaxified and cut into 4 to $5 \mu \mathrm{m}$ slices by microtome. Subsequently, uterine slices were stained with hematoxylin and eosin (H\&E).

\subsection{Wet to Dry (W/D) Weight Ratio MPO Assay}

Uteri were washed thrice with PBS and weighed; the weight was recorded as wet weight. Formerly, uteri were retained in an oven of $80{ }^{\circ} \mathrm{C}$ for $24 \mathrm{~h}$; the weight was recorded as dry weight. The uterine edema was calculated as $\mathrm{W} / \mathrm{D}$ ratio. The uterine tissues were homogenized $(w / v, 1 / 9)$ to measure the MPO activity assay according to supplier instructions.

\subsection{ELISA Assay}

The levels of pro-inflammatory markers (IL-1 $\beta$, IL-6 and TNF- $\alpha$ ), anti-inflammatory

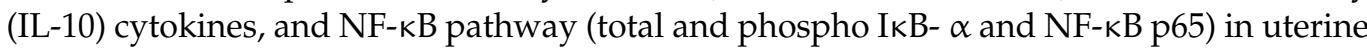
tissue were measured in triplicate by ELISA kits following manufacturer's guidelines.

\subsection{Real-Time Quantitative RCR Assay}

Total RNA from uterine tissue was harvested by TRIzol (Invitrogen, Carlsbad, CA, USA). The complementary DNA was then synthesized from extracted RNA. The expression of TLR4, pro, and anti-inflammatory mediators were detected and quantified by using SYBR Green Master Mix (TaKaRa Biotechnology, Tokyo, Japan) according to guidelines provided by the manufacturer. The primers employed in this study are mentioned in Table 1. GAPDH was used as a control. The data values were calculated using the $2^{-\Delta \Delta C T}$ method according to the previous study [16]. 
Table 1. The primers used for RT-qPCR assay.

\begin{tabular}{|c|c|c|c|c|}
\hline Target Gene & Primer & Primer Sequence $\left(5^{\prime} \rightarrow 3^{\prime}\right)$ & Accession No. & Product Size \\
\hline TLR4 & $\begin{array}{l}\text { Forward } \\
\text { Reverse }\end{array}$ & $\begin{array}{l}\text { TTCAGAGCCGTTGGTGTATC } \\
\text { CTCCCATTCCAGGTAGGTGT }\end{array}$ & NM_021297.2 & 170 \\
\hline$T N F-\alpha$ & $\begin{array}{l}\text { Forward } \\
\text { Reverse }\end{array}$ & $\begin{array}{l}\text { CTTCTCATTCCTGCTTGTG } \\
\text { ACTTGGTGGTTTGCTACG }\end{array}$ & NM_013693.3 & 198 \\
\hline$I L-1 \beta$ & $\begin{array}{l}\text { Forward } \\
\text { Reverse }\end{array}$ & $\begin{array}{l}\text { CCTGGGCTGTCCTGATGAGAG } \\
\text { TCCACGGGAAAGACACAGGTA }\end{array}$ & NM_008361.4 & 131 \\
\hline$I L-6$ & $\begin{array}{l}\text { Forward } \\
\text { Reverse }\end{array}$ & $\begin{array}{l}\text { GGCGGATCGGATGTTGTGAT } \\
\text { GGACCCCAGACAATCGGTTG }\end{array}$ & NM_031168.1 & 199 \\
\hline$I L-10$ & $\begin{array}{l}\text { Forward } \\
\text { Reverse }\end{array}$ & $\begin{array}{c}\text { ACAGCCGGGAAGACAATAACT } \\
\text { GCAGCTCTAGGAGCATGTGG }\end{array}$ & NM_010548.2 & 66 \\
\hline GAPDH & $\begin{array}{l}\text { Forward } \\
\text { Reverse }\end{array}$ & $\begin{array}{c}\text { GTGGCAAAGTGGAGATTGTTG } \\
\text { TTGACTGTGCCGTTGAATTTG }\end{array}$ & NM_001289726.1 & 109 \\
\hline
\end{tabular}

\subsection{Western Blot}

The total protein from uterine tissue was harvested using a RIPA lysis solution (Beyotime Biotechnology, Shanghai, China) containing a phosphatase inhibitor. A BCA kit (Vazyme Biotech, Nanjing, China) was used for the determination of protein concentration. Subsequently, equal quantities in terms of protein concentration were loaded and fractionated on SDS-PAGE. Next, the protein was transfer to PVDF membrane. Nonprotein parts of the membranes were blocked by skimmed milk (5\%) for $2 \mathrm{~h}$. Then, the membranes were probed with primary antibodies at $4{ }^{\circ} \mathrm{C}$ overnight. The TBST was washing of membranes (thrice; $10 \mathrm{~min}$ each). The membranes were incubated with a secondary antibody for $1 \mathrm{~h}$ at room temperature. The expression profile of protein was measured by an ECL Plus Western blot detection system.

\subsection{Statistical Analysis}

Three independent replicates were used in each experiment. GraphPad Prism 8.02 (San Diego, CA, USA) was used for the assessment of data. One-way analysis of variance (ANOVA) followed by Dunnet's multiple comparison test were employed in a Gaussian distribution pattern. The data values are mentioned as mean \pm Standard Error of Mean (S.E.M.). The $p$-value of $(<0.05)$ was considered statistically significant.

\section{Results}

\subsection{GnRb1 Alleviates LPS-Induced Murine Endometritis}

The effect of GnRb1 against LPS-triggered uterine injury can be obviously seen in Figure 2A. No histopathological alterations were observed in the control group (Figure 2B). However, pathological changes, i.e., hyperemia, hemorrhages, edema, and penetration of inflammatory cells, were detected in the LPS-administrated group (Figure 2C). The LPS-caused histopathological alterations were drastically alleviated by GnRb1 at the dose rate of 25 and $50 \mathrm{mg} / \mathrm{kg}$ (Figure 2D,E). To confirm these findings, a histopathological score was recorded according to the previous study [17] (Figure 2F). Accumulatively, these findings show that GnRb1 efficiently ameliorated LPS-stimulated endometritis. 

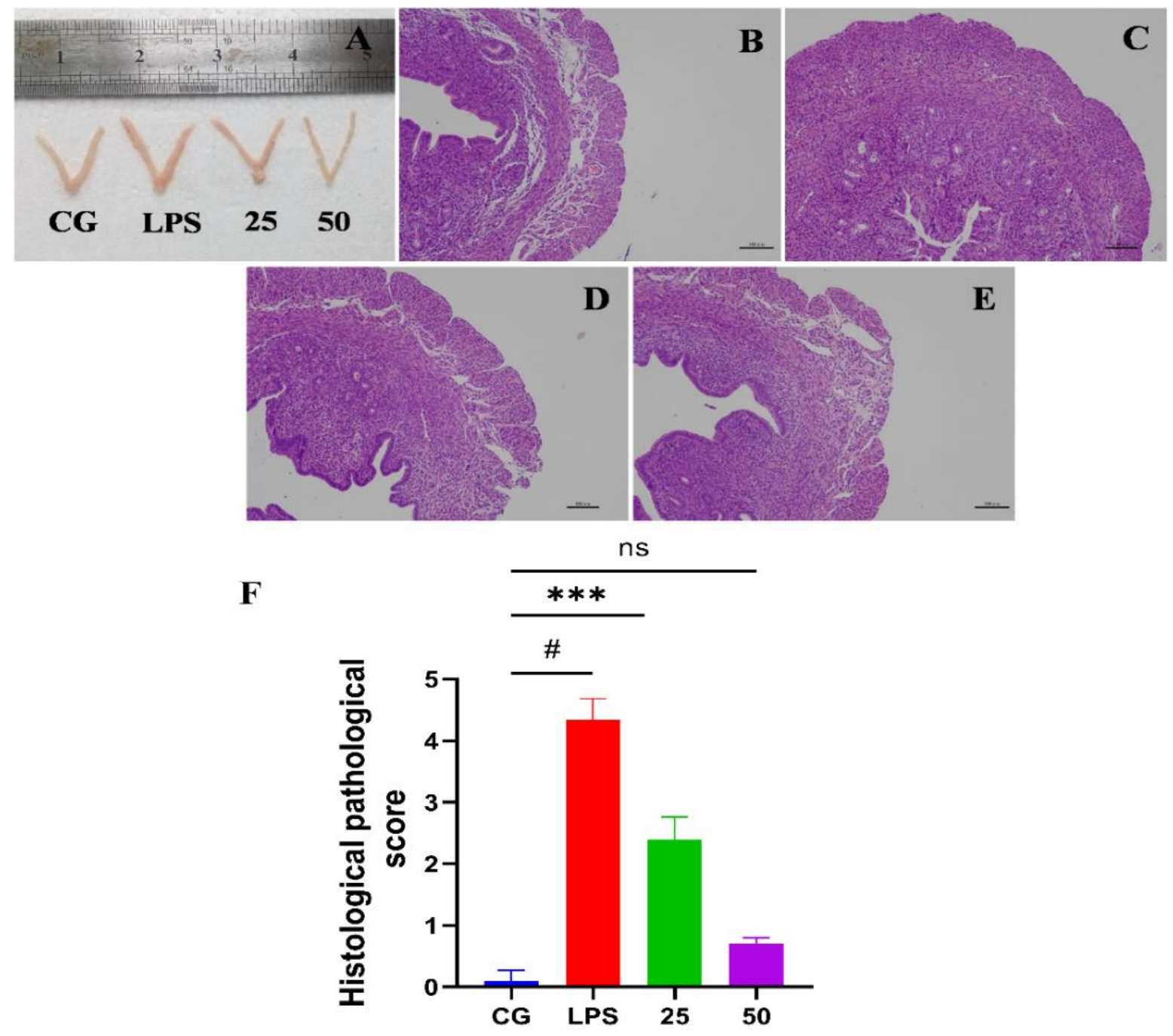

Figure 2. Effects of GnRb1 against LPS-triggered uterine injury. (A) The morphology of uterine tissue. (B) The control group (CG). (C) The LPS group. (D,E) The LPS + GnRb1 (25 and $50 \mathrm{mg} / \mathrm{kg}$, respectively). (F) Histopathological score of uterine sections. The scale bar is of $100 \mu \mathrm{m}(200 \times$ magnification). CG represents the control group. LPS reveals the LPS-induced groups. The 25 and 50 are the GnRb1-administrated groups representing $25 \mathrm{mg} / \mathrm{kg}$ and $50 \mathrm{mg} / \mathrm{kg}$ per animal, respectively. $\mathrm{GnRb1}$ indicates the Ginsenoside Rb1. Data statistics are demonstrated as mean \pm S.E.M. The \# $p<0.001 \mathrm{CG}$ versus LPS group, ${ }^{* * *} p<0.001$ and ns indicates the nonsignificant difference between CG versus LPS + GnRb1 groups.

\subsection{Effect of GnRb1 against LPS-Induced MPO Activity and W/D Ratio}

MPO activity is a marker of neutrophilic (the first line of defense) penetration. The results revealed that LPS immensely $(p<0.05)$ boosted the MPO activity in uterine tissue compared to the control group. Nevertheless, GnRb1 therapy sharply $(p<0.05)$ decreased the MPO activity, as indicated in Figure 3A. Edema is a peculiar sign of LPS-mediated inflammation [10]. The $\mathrm{W} / \mathrm{D}$ ratio of uterine tissue was measured to uterine edema. The $\mathrm{W} / \mathrm{D}$ ratio was significantly $(p<0.05)$ improved in the LPS group compared with the control group. However, the uterine W/D ratio was reduced significantly $(p<0.05)$ in both GnRb1-treated (25 and $50 \mathrm{mg} / \mathrm{kg}$ ) groups, as shown in Figure 3B. 

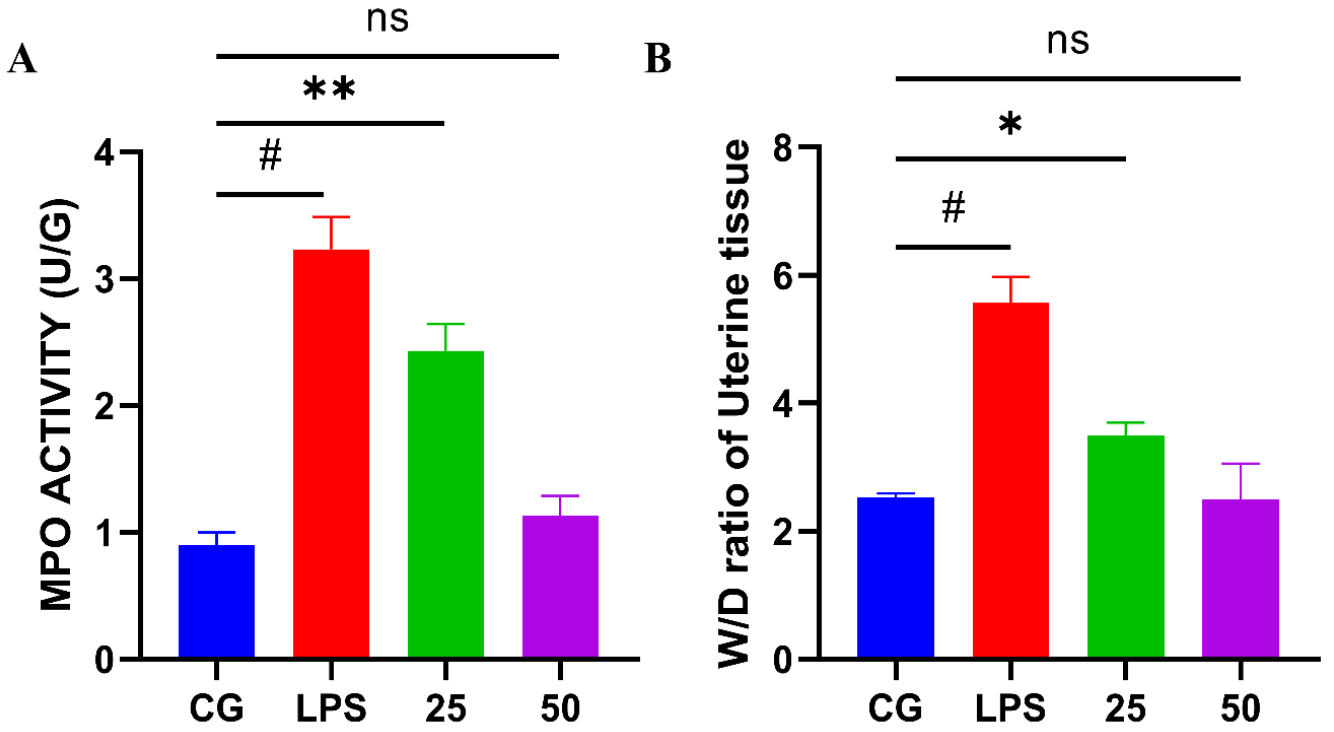

Figure 3. Consequence of $\mathrm{GnRb} 1$ against MPO activity assay and $\mathrm{W} / \mathrm{D}$ ratio in mice uterus. (A) MPO (U/G) activity. (B) W/D ratio. CG represents the control group. LPS reveals the LPS-induced groups. The 25 and 50 are the GnRb1-administrated groups representing $25 \mathrm{mg} / \mathrm{kg}$ and $50 \mathrm{mg} / \mathrm{kg}$ per animal, respectively. GnRb1 indicates the Ginsenoside Rb1. MPO indicates the myeloperoxidase, whereas $\mathrm{W} / \mathrm{D}$ depicts the wet to dry weight ratio. Data statistics are demonstrated as mean \pm S.E.M. The $\# p<0.001$ CG versus LPS group, ${ }^{*} p<0.05,{ }^{* *} p<0.01$, and ns indicates the nonsignificant difference between CG versus LPS + GnRb1 groups.

\subsection{Effect of GnRb1 against LPS-Induced Expression of Pro- and Anti-Inflammatory Markers}

Pro- and anti-inflammatory mediators are directly involved in the development of endometritis [18]. To investigate the protective properties of GnRb1, the concentration and gene expression level of pro-inflammatory mediators have been measured by ELISA and RT-qPCR assay, respectively. The findings of the ELISA assay indicated that GnRb1 therapy significantly $(p<0.05)$ suppressed the concentrations of TNF- $\alpha$ (Figure $4 \mathrm{~A})$, IL-1 $\beta$ (Figure 4B), and IL-6 (Figure 4C), which were increased by LPS. These findings were further confirmed by gene expression via an RT-qPCR assay. Interestingly, a similar trend was noticed as a result of the ELISA assay. Compared with the control group, the LPS group obviously $(p<0.05)$ increased the gene expressions of TNF- $\alpha$ (Figure $4 \mathrm{D})$, IL-1 $\beta$ (Figure $4 \mathrm{E}$ ), and IL-6 (Figure 4F), which were attenuated significantly $(p<0.05)$ by GnRb1 treatment in a dose-dependent manner.

Conversely, GnRb1 increased $(p<0.05)$ the concentration of the IL-10 in LPS-administrated groups (Figure 5A), as well as the mRNA expression level of IL-10 (Figure 5B) in a dosedependent pattern. These findings indicated that GnRb1 attenuated the production of proinflammatory mediators and boosted anti-inflammatory cytokine production.

\subsection{GnRb1 Suppresses LPS-Induced Activation of NF- $\kappa B$ Signaling Pathway}

The anti-inflammatory properties of $\mathrm{GnRb} 1$ were investigated by determining the

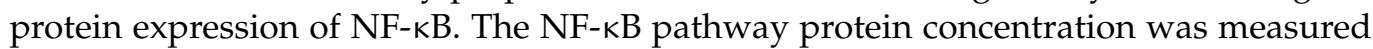
by ELISA assay. The protein expression of the phosphorylated form of IkB- $\alpha$ (Figure 7A) and NF- $\kappa$ B p65 (Figure 7B) protein were significantly higher $(p<0.05)$ in LPS-challenged groups. In contrast, the levels of these proteins were markedly decreased $(p<0.05)$ in GnRb1-treated groups. 
A

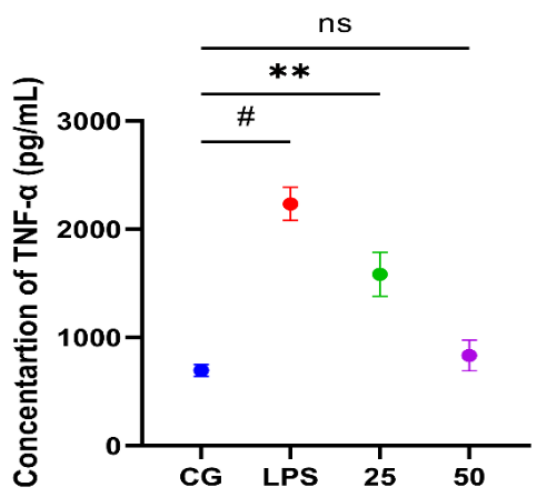

B

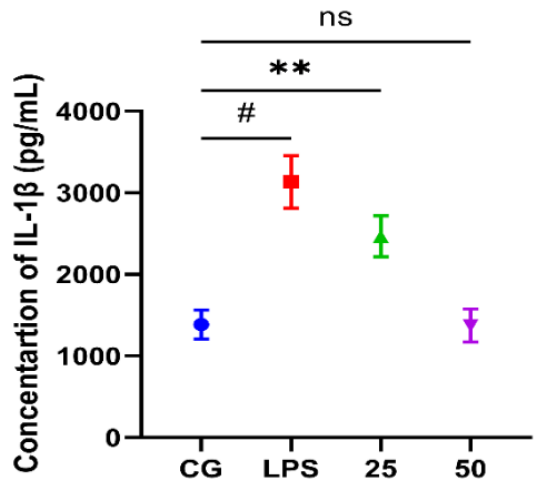

C

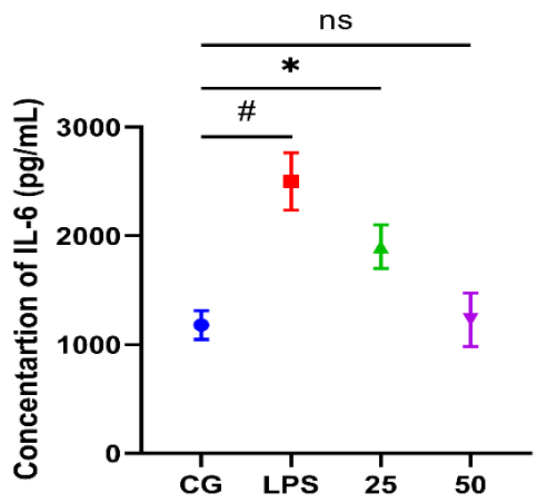

D

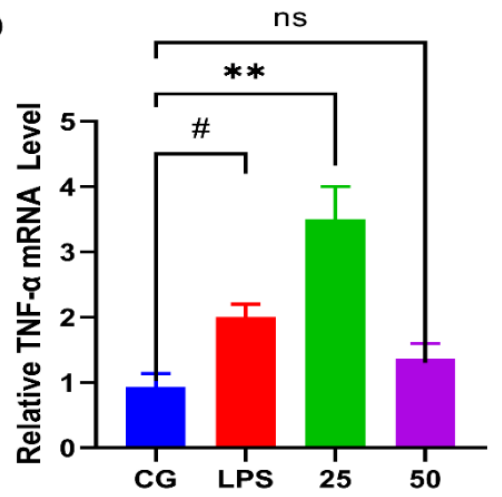

$\mathbf{E}$

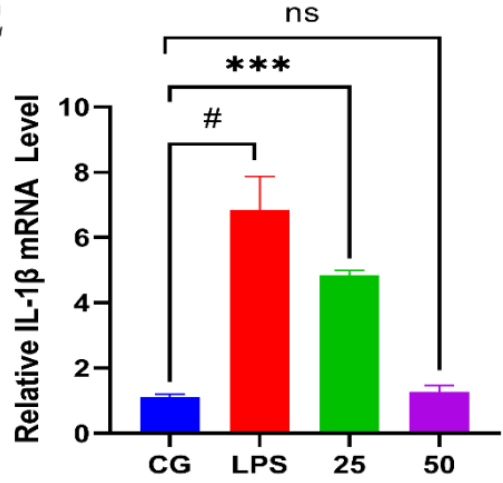

$\mathbf{F}$

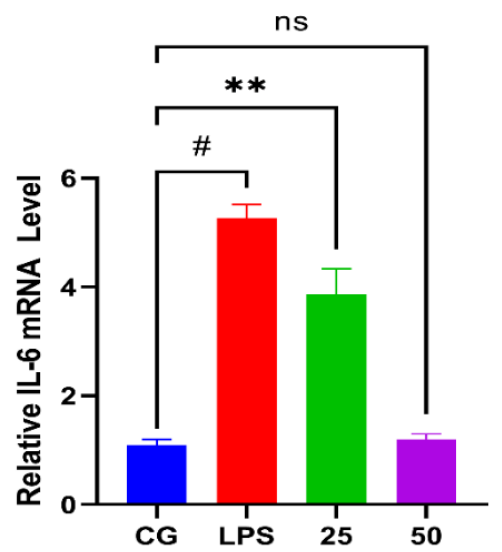

Figure 4. Effects of GnRb1 against LPS-induced production of pro-inflammatory cytokines. The concentration of: (A) the TNF- $\alpha(\mathrm{pg} / \mathrm{mL}) ;(\mathbf{B})$ the IL-1 $\beta(\mathrm{pg} / \mathrm{mL})$; and (C) IL-6 $(\mathrm{pg} / \mathrm{mL})$. The relative mRNA expression levels of (D) TNF- $\alpha$, (E) IL-1 $\beta$; and (F) IL-6. CG represents the control group. LPS reveals the LPS-induced groups. The 25 and 50 are the GnRb1-administrated groups representing $25 \mathrm{mg} / \mathrm{kg}$ and $50 \mathrm{mg} / \mathrm{kg}$ per animal, respectively. GnRb1 indicates the Ginsenoside Rb1. Data statistics are demonstrated as mean \pm S.E.M. The $\# p<0.001$ CG versus LPS group, ${ }^{*} p<0.05$, ${ }^{* *} p<0.01$, ${ }^{* * *} p<0.001$, and ns indicates the nonsignificant difference between CG versus LPS + GnRb1 groups. 
A

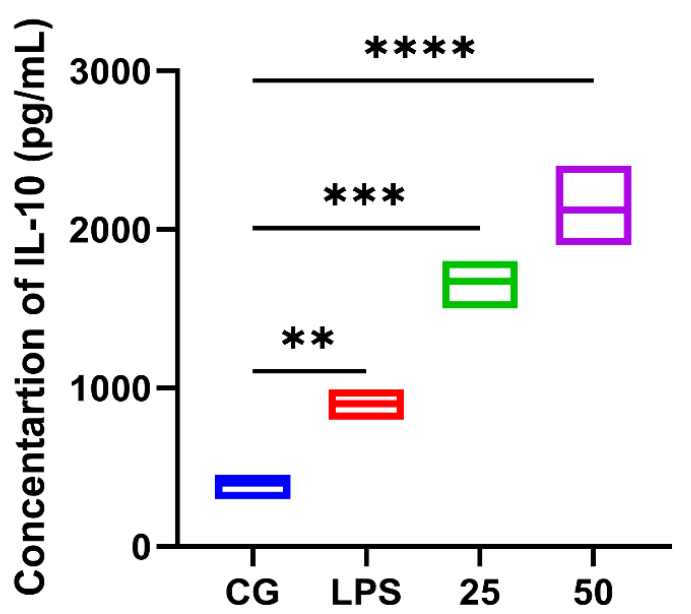

B

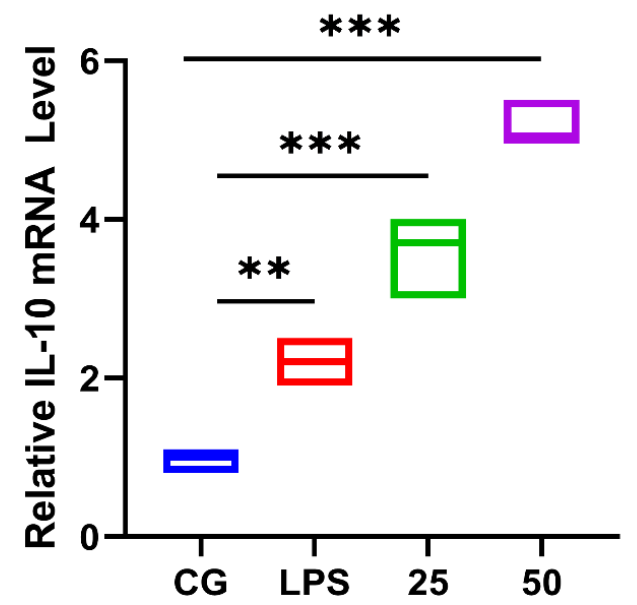

Figure 5. Effects of GnRb1 against LPS-induced production IL-10 concentration. The concentration of (A) IL-10 (pg/mL). The relative mRNA expression level of (B) IL-10 in uterine tissue. CG represents the control group. LPS reveals the LPS-induced groups. The 25 and 50 are the GnRb1-administrated groups representing $25 \mathrm{mg} / \mathrm{kg}$ and $50 \mathrm{mg} / \mathrm{kg} \mathrm{per} \mathrm{animal,}$ respectively. GnRb1 indicates the Ginsenoside Rb1. Data statistics are demonstrated as mean \pm S.E.M. The ${ }^{* *} p<0.001 \mathrm{CG}$ versus LPS group, ${ }^{* *} p<0.01,{ }^{* * *} p<0.001,{ }^{* * *} p<0.0001$, and ns indicates the nonsignificant difference between CG versus LPS + GnRb1 groups.

\subsection{GnRb1 Represses LPS-Induced TLR4 Expression}

TLR4 is activated as the host defense mechanism against LPS. As displayed in the results of RT-qPCR (Figure 6A) as well as Western blot assay (Figure 6B), TLR4 expression was dramatically increased $(p<0.05)$ in the LPS group. However, GnRb1 therapy suppressed $(p<0.05)$ the LPS-stimulated TLR4 expression.

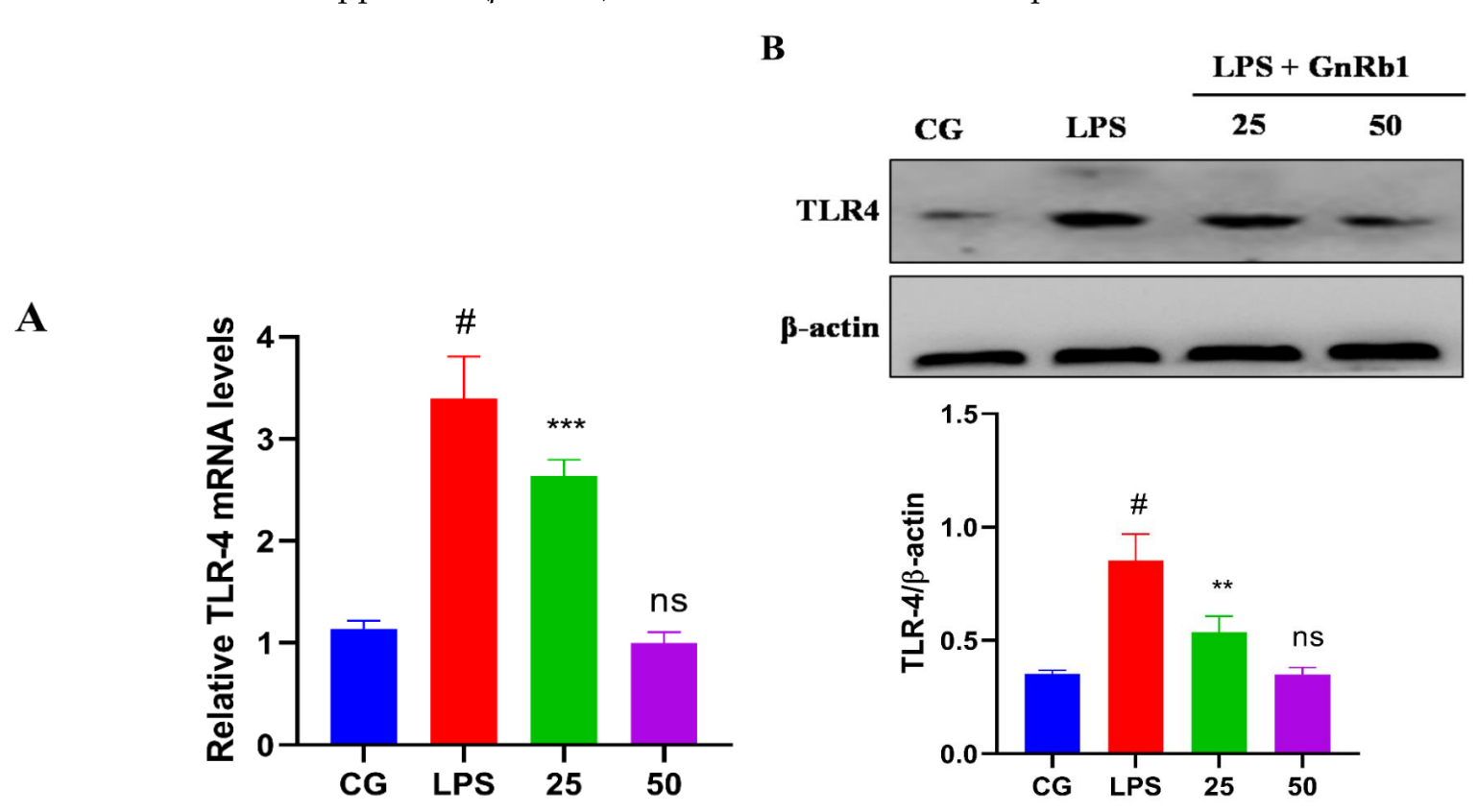

Figure 6. Effects of GnRb1 against LPS-induced expression of the TLR4. (A) The relative mRNA expression level of the TLR4 gene. (B) The protein expression of TLR4. CG represents the control group. LPS reveals the LPS-induced groups. The 25 and 50 are the GnRb1-administrated groups representing $25 \mathrm{mg} / \mathrm{kg}$ and $50 \mathrm{mg} / \mathrm{kg}$ per animal, respectively. GnRb1 indicates the Ginsenoside Rb1. Data statistics are demonstrated as mean \pm S.E.M. The \# $p<0.001$ CG versus LPS group, ${ }^{* *} p<0.01,{ }^{* * *} p<0.001$, and ns indicates the nonsignificant difference between CG versus LPS + GnRb1 groups. 
A

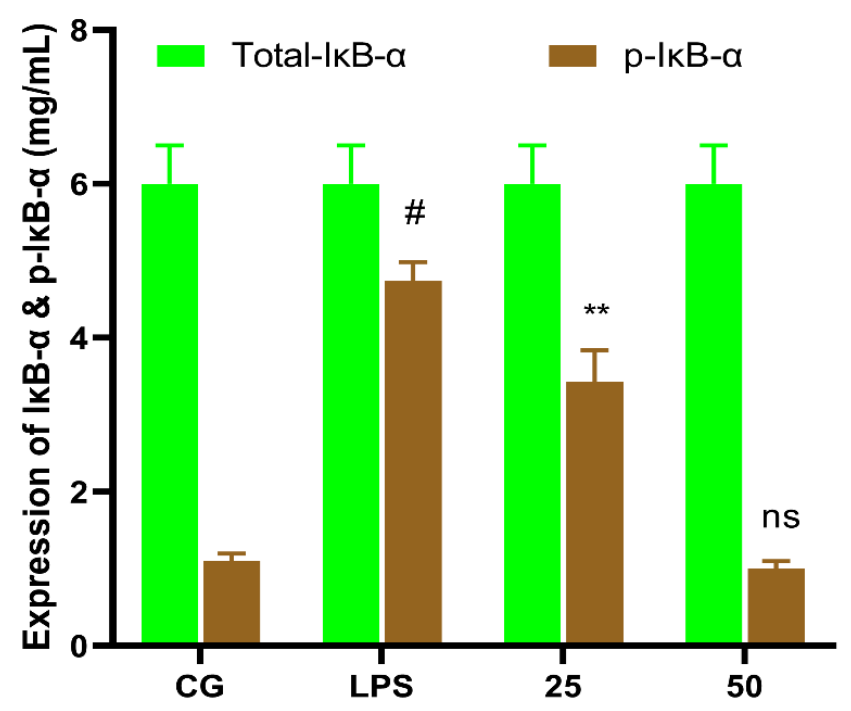

B

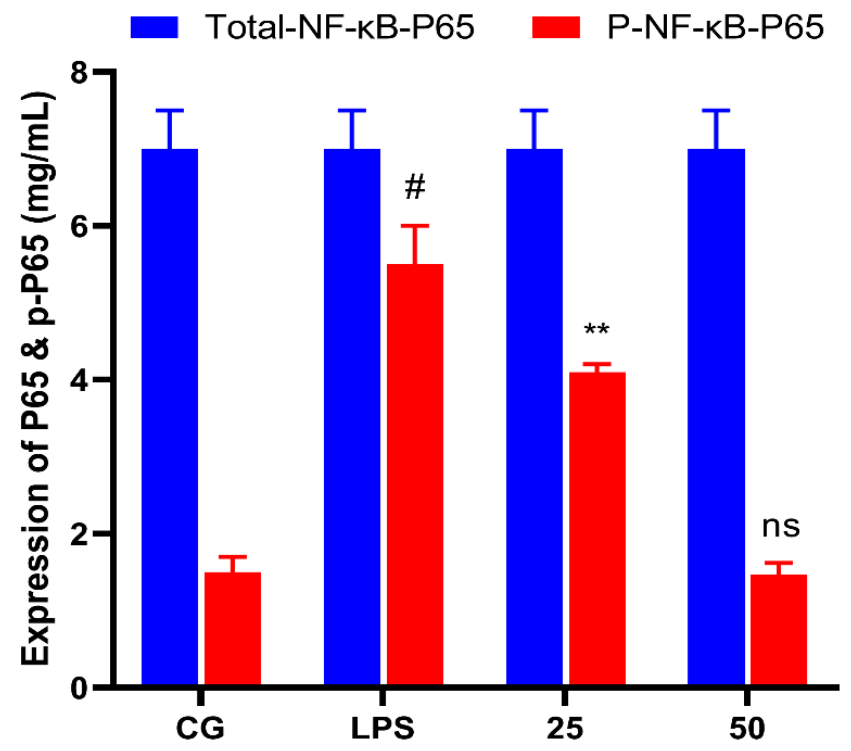

Figure 7. Effects of $\mathrm{GnRb} 1$ against LPS-induced expression NF- $\mathrm{B}$ p pathway proteins measured by ELISA. (A) The expression levels of the NF- $\kappa B$ p65 and its phosphorylated (p-NF- $\mathrm{B}$ p65) form. (B) The expression levels of total $I \kappa B \alpha$ and its phosphorylated ( $p-I \kappa B \alpha)$ form. CG represents the control group. LPS reveals the LPS-induced groups. The 25 and 50 are the GnRb1-administrated groups representing $25 \mathrm{mg} / \mathrm{kg}$ and $50 \mathrm{mg} / \mathrm{kg}$ per animal, respectively. GnRb1 indicates the Ginsenoside $\mathrm{Rb} 1$. Data statistics are demonstrated as mean \pm S.E.M. The \# $p<0.001 \mathrm{CG}$ versus LPS group, ** $p<0.01$, and $n s$ indicates the nonsignificant difference between CG versus LPS + GnRb1 groups.

\section{Discussion}

Pathogenesis triggered by microbes is important in the progression of inflammation [19]. Inflammation is a protective and defensive mechanism of the host immune system. However, massive inflammation might pose lethal effects on the structure and physiology of tissue. Endometritis is a major factor causing infertility in humans and animals [20]. Endometritis is characterized by foul-smelling and pyogenic uterine secretion associated with a high body temperature, depression, and dehydration [21]. LPS is derived from the cell wall of G-ve bacteria and is used widely to study mechanisms of inflammatory diseases [22-24]. In the recent era, bacterial resistance and drug residues owing to the undue usage of antibiotics have become a major concern globally for the dairy industry [25]. 
Therefore, there is currently a need to identify and develop new therapeutic agents that are more effective and safe to treat endometritis. Recently, traditional Chinese herbs have gained much attention due to their safe and heathy usage in food animals [24]. GnRb1 is a glycoside from the class of triterpenoid saponins, found in Panax ginseng, that has a long history of being used in China to cure various ailments. Its main biopharmacological properties includes cardioprotective [26,27], neuroprotective [28,29], nephroprotective [30], immunoregulatory [31], and anti-inflammatory properties [15,32,33]. GnRb1 was proved to suppress LPS-induced ALI [12]. Therefore, we presumed that GnRb1 might be a good anti-inflammatory herbal medicine. This is the first study to explore the anti-inflammatory properties of $\mathrm{GnRb} 1$ in a murine model of endometritis.

In the current study, hyperemia, hemorrhage, endothelial wall disruption, and massive neutrophil infiltration were observed in the LPS group. The LPS-stimulated histopathological changes were markedly alleviated by GnRb1 treatment. The characteristic pathological features of LPS-stimulated endometritis include infiltration of neutrophils, secretion of chemokines and cytokines, and edema [34]. MPO activity is a biomarker of the accumulation of neutrophils during acute inflammation caused by S. aureus [32,33] and E. coli $[5,8]$. The results indicated that MPO activity was increased in the LPS group. However, the elevated levels of MPO were suppressed by the administration of GnRb1, which means that GnRb1 suppress the inflammation in the uterine tissue. The uterine W/D ratio is sharply increased in LPS-challenged murine uteri, but W/D ratio is dramatically decreased upon $\mathrm{GnRb} 1$ therapy. It suggested that $\mathrm{GnRb} 1$ effectively alleviated endometritis by suppressing uterine edema and MPO activity.

TLR4 is a vital receptor to be activated in the LPS-triggered host defense mechanism. It is evidenced from the results of many studies that once TLR4 is activates, it triggers the activation of the downstream pathways, including the NF- $\mathrm{kB}$ pathway [35-37]. Therefore, it is hypothesized to determine whether the anti-inflammatory properties of $\mathrm{GnRb} 1$ will be achieved through the TLR4-mediated NF-KB pathway. It is revealed the LPS-challenged uteri experienced boosted gene and protein expression of TLR4, but that was suppressed by $\mathrm{GnRb} 1$ administration. The NF- $\mathrm{KB}$ pathway is one of the main crucial inflammatory pathways that is activated by G-ve bacteria via the regulation of TLR4 receptors [38,39]. During normal physiological conditions, NF- $\mathrm{kB}$ p 65 and I $\mathrm{k} \mathrm{B} \alpha$ are localized in the cytoplasm of the cell [23]. Upon stimulation via TLRs, these proteins were phosphorylated and the NF- $\kappa B$ p 65 subunit dissociated from I $\kappa B \alpha$. Phosphorylated NF- $\kappa B$ p 65 is then transferred to the nucleus to regulate the production of many inflammatory mediators, including IL- $1 \beta$, IL-6, and TNF- $\alpha[40,41]$. The findings of the current study suggest that GnRb1 remarkably ameliorated the phosphorylation of the NF- $\mathrm{kB}$ p 65 and IкB $\alpha$.

Pro-inflammatory mediators perform an essential role in the development of inflammatory diseases, such as mastitis [34,42], ALI [43], and endometritis [5,44]. TNF- $\alpha$ is released from macrophages, monocyte, and T-lymphocytes during the initial stage of inflammation and has a role in neutrophil activation and the secretion of other proinflammatory cytokines [45]. IL- $1 \beta$ regulates the inflammatory responses, also produced from macrophages [46]. IL-6 is produced during stress, trauma, infections, etc., and is thought to maintain tissue injury [47]. The results of the present research indicated that pro-inflammatory mediators (IL-1 $\beta$, IL-6, and TNF- $\alpha$ ) in the uterine tissue were dosedependently and dramatically repressed in the GnRb1 group. Surprisingly, it was observed that IL-10 was boosted in terms of expression during the LPS challenge, which shows that IL-10 is an anti-inflammatory cytokine. The elevated level of the IL-10 in GnRb1 groups dose-dependently suggested that $\mathrm{GnRb} 1$ has anti-inflammatory properties. These findings suggested that GnRb1-elicited anti-inflammatory effects might be due to the suppression of levels of pro-inflammatory cytokines. It was observed that GnRb1 protects from LPS-induced uterine inflammation. Therefore, it is believed that $\mathrm{GnRb} 1$ attenuates extensive inflammatory reactions triggered by LPS in uterine tissue via the suppression of the TLR4-mediated NF-kB pathway. 


\section{Conclusions}

In conclusion, the current research is the first study to confirm that GnRb1 exerts protective effects against LPS-induced endometritis in mice. The protective properties of GnRb1 might be due to improvements in histopathological alterations, MPO activity, and uterine edema. Moreover, GnRb1 has the potential to inhibit the secretion of proinflammatory cytokines and enhance the production of anti-inflammatory mediators. Furthermore, the promising anti-inflammatory effect of $\mathrm{GnRb} 1$ was via the TLR4-mediated NF- $\mathrm{KB}$ pathway. Taken together, GnRb1 might be a potent anti-inflammatory drug to treat endometritis in both humans and animals.

Author Contributions: A.S., I.S. (Irfan Shaukat), X.Z. and L.Y. contributed to the conception and design of the study. A.S., C.C., X.S., T.Y., K.N. and Z.Y. performed assays and furnished the lab study. X.G., J.Z., U.R., M.A. and A.S. performed data collection. S.H., I.S. (Imaran Shaukat), M.S. and S.A.R. conducted data analysis. A.S., M.S., M.A., S.S. and R.S. drafted the manuscript. S.S. and M.S. drafted the revised version of the manuscript. A.S. wrote the manuscript and holds primary responsibility for the final content. All authors have read and agreed to the published version of the manuscript.

Funding: This study was supported by China Agriculture Research System of MOF and MARA, and the Fundamental Research Funds for the Central Universities (2662019PY014).

Institutional Review Board Statement: Experiments regarding animals were carried out after being approved by the institutional research ethics and animal welfare committee, Huazhong Agricultural University (HZAUMO_2015-12) (Wuhan, China).

Informed Consent Statement: Not applicable.

Data Availability Statement: Data are contained within the article.

Conflicts of Interest: The authors declare no conflict of interest.

Sample Availability: Samples of the compounds are not available from the authors.

\section{References}

1. Wu, H.; Dai, A.; Chen, X.; Yang, X.; Li, X.; Huang, C.; Jiang, K.; Deng, G. Leonurine ameliorates the inflammatory responses in lipopolysaccharide-induced endometritis. Int. Immunopharmacol. 2018, 61, 156-161. [CrossRef]

2. Wang, X.; Yuan, T.; Yin, N.; Ma, X.; Yang, Y.; Yang, J.; Shaukat, A.; Deng, G. Interferon- $\tau$ regulates the expression and function of bovine leukocyte antigen by downregulating bta-miR-204. Exp. Ther. Med. 2021, 21, 594. [CrossRef]

3. Mohammed, Z.; Mann, G.; Robinson, R. Impact of endometritis on post-partum ovarian cyclicity in dairy cows. Vet. J. 2019, 248, 8-13. [CrossRef] [PubMed]

4. Liang, Y.; Shen, T.; Ming, Q.; Han, G.; Zhang, Y.; Liang, J.; Zhu, D. Alpinetin ameliorates inflammatory response in LPS-induced endometritis in mice. Int. Immunopharmacol. 2018, 62, 309-312. [CrossRef] [PubMed]

5. Zhang, H.; Wu, Z.M.; Yang, Y.P.; Shaukat, A.; Yang, J.; Guo, Y.F.; Zhang, T.; Zhu, X.Y.; Qiu, J.X.; Deng, G.Z.; et al. Catalpol ameliorates LPS-induced endometritis by inhibiting inflammation and TLR4/NF-kappaB signaling. J. Zhejiang Univ. Sci. B 2019, 20, 816-827. [CrossRef] [PubMed]

6. Jiang, K.; Guo, S.; Yang, J.; Liu, J.; Shaukat, A.; Zhao, G.; Wu, H.; Deng, G. Matrine alleviates Staphylococcus aureus lipoteichoic acid-induced endometritis via suppression of TLR2-mediated NF-kB activation. Int. Immunopharmacol. 2019, 70, $201-207$. [CrossRef]

7. Yin, N.; Yang, Y.; Wang, X.; Yang, C.; Ma, X.; Shaukat, A.; Zhao, G.; Deng, G. MiR-19a mediates the negative regulation of the NF-кB pathway in lipopolysaccharide-induced endometritis by targeting TBK1. Inflamm. Res. 2019, 68, 231-240. [CrossRef]

8. Yang, Y.; Yang, C.; Guo, Y.F.; Liu, P.; Guo, S.; Yang, J.; Zahoor, A.; Shaukat, A.; Deng, G. MiR-142a-3p alleviates Escherichia coli derived lipopolysaccharide-induced acute lung injury by targeting TAB2. Microbial Pathog. 2019, 136, 103721. [CrossRef]

9. Guo, S.; Chen, Y.; Liu, J.; Yang, J.; Yang, C.; Zhang, T.; Jiang, K.; Wu, Z.; Shaukat, A.; Deng, G. miR-497a-5p attenuates lipopolysaccharide-induced inflammatory injury by targeting IRAK2. J. Cell. Physiol. 2019, 234, 22874-22883. [CrossRef]

10. Liu, J.; Guo, S.; Jiang, K.; Zhang, T.; Zhiming, W.; Yaping, Y.; Jing, Y.; Shaukat, A.; Deng, G. miR-488 mediates negative regulation of the AKT/NF-кB pathway by targeting Rac1 in LPS-induced inflammation. J. Cell. Physiol. 2020, 235, 4766-4777. [CrossRef]

11. Shaukat, A.; Guo, Y.F.; Jiang, K.; Zhao, G.; Wu, H.; Zhang, T.; Yang, Y.; Guo, S.; Yang, C.; Zahoor, A.; et al. Ginsenoside $\mathrm{Rb} 1$ ameliorates Staphylococcus aureus-induced Acute Lung Injury through attenuating NF-kappaB and MAPK activation. Microbial Pathog. 2019, 132, 302-312. [CrossRef]

12. Yuan, Q.; Jiang, Y.W.; Ma, T.T.; Fang, Q.H.; Pan, L. Attenuating effect of Ginsenoside Rb1 on LPS-induced lung injury in rats. J. Inflamm. 2014, 11, 40. [CrossRef] [PubMed] 
13. Wu, Y.; Yu, Y.; Szabo, A.; Han, M.; Huang, X.-F. Central inflammation and leptin resistance are attenuated by ginsenoside Rb1 treatment in obese mice fed a high-fat diet. PLOS ONE 2014, 9, e92618. [CrossRef] [PubMed]

14. Lee, J.S.; Song, J.H.; Sohn, N.W.; Shin, J.W. Inhibitory effects of ginsenoside Rb1 on neuroinflammation following systemic lipopolysaccharide treatment in mice. Phytother. Res. 2013, 27, 1270-1276. [CrossRef] [PubMed]

15. Zhu, J.; Jiang, Y.; Wu, L.; Lu, T.; Xu, G.; Liu, X. Suppression of local inflammation contributes to the neuroprotective effect of ginsenoside $\mathrm{Rb} 1$ in rats with cerebral ischemia. Neuroscience 2012, 202, 342-351. [CrossRef] [PubMed]

16. Rajput, S.A.; Zhang, C.; Feng, Y.; Wei, X.T.; Khalil, M.M.; Rajput, I.R.; Baloch, D.M.; Shaukat, A.; Rajput, N.; Qamar, H.; et al. Proanthocyanidins Alleviates AflatoxinB ${ }_{1}$-Induced Oxidative Stress and Apoptosis through Mitochondrial Pathway in the Bursa of Fabricius of Broilers. Toxins 2019, 11, 157. [CrossRef]

17. Hu, X.; Li, D.; Wang, J.; Guo, J.; Li, Y.; Cao, Y.; Zhang, N.; Fu, Y. Melatonin inhibits endoplasmic reticulum stress-associated TXNIP/NLRP3 inflammasome activation in lipopolysaccharide-induced endometritis in mice. Int. Immunopharmacol. 2018, 64, 101-109. [CrossRef]

18. Gugliandolo, E.; Fusco, R.; Licata, P.; Peritore, A.F.; D’amico, R.; Cordaro, M.; Siracusa, R.; Cuzzocrea, S.; Crupi, R. Protective Effect of Hydroxytyrosol on LPS-Induced Inflammation and Oxidative Stress in Bovine Endometrial Epithelial Cell Line. Vet. Sci. 2020, 7, 161. [CrossRef]

19. Dong, H.; Ijaz, M.; Mehmood, K.; Ali, M.; Tian, F.; Li, J.; Ahmed, S.; Shaukat, A.; Chang, Z.; Wu, Q. Protective effects of salidroside and dexamethasone against E. coli-induced inflammatory response on endometrial epithelium cells in yaks. Pak. Vet. J. 2019, 39, 101-105. [CrossRef]

20. Carneiro, L.C.; Cronin, J.G.; Sheldon, I.M. Mechanisms linking bacterial infections of the bovine endometrium to disease and infertility. Reprod. Biol. 2016, 16, 1-7. [CrossRef]

21. Wu, H.; Zhao, G.; Jiang, K.; Li, C.; Qiu, C.; Deng, G. Engeletin alleviates lipopolysaccharide-induced endometritis in mice by inhibiting TLR4-mediated NF-кB activation. J. Agric. Food Chem. 2016, 64, 6171-6178. [CrossRef]

22. Zhao, G.; Jiang, K.; Yang, Y.; Zhang, T.; Wu, H.; Shaukat, A.; Qiu, C.; Deng, G. The potential therapeutic role of miR-223 in bovine endometritis by targeting the NLRP3 inflammasome. Front. Immunol. 2018, 9, 1916. [CrossRef] [PubMed]

23. Jiang, K.; Guo, S.; Zhang, T.; Yang, Y.; Zhao, G.; Shaukat, A.; Wu, H.; Deng, G. Downregulation of TLR4 by miR-181a provides negative feedback regulation to lipopolysaccharide-induced inflammation. Front. Pharmacol. 2018, 9, 142. [CrossRef] [PubMed]

24. Jiang, K.; Guo, S.; Yang, C.; Yang, J.; Chen, Y.; Shaukat, A.; Zhao, G.; Wu, H.; Deng, G. Barbaloin protects against lipopolysaccharide (LPS)-induced acute lung injury by inhibiting the ROS-mediated PI3K/AKT /NF-кB pathway. Int. Immunopharmacol. 2018, 64, 140-150. [CrossRef]

25. Li, W.; Fu, K.; Lv, X.; Wang, Y.; Wang, J.; Li, H.; Tian, W.; Cao, R. Lactoferrin suppresses lipopolysaccharide-induced endometritis in mice via down-regulation of the NF-kappaB pathway. Int. Immunopharmacol. 2015, 28, 695-699. [CrossRef] [PubMed]

26. Zheng, X.; Wang, S.; Zou, X.; Jing, Y.; Yang, R.; Li, S.; Wang, F. Ginsenoside Rb1 improves cardiac function and remodeling in heart failure. Exp. Anim. 2017, 66, 217-228. [CrossRef]

27. Liu, Z.; Song, L.; Zhang, P.; Cao, Z.; Hao, J.; Tian, Y.; Luo, A.; Zhang, P.; Ma, J. Ginsenoside Rb1 exerts antiarrhythmic effects by inhibiting I(Na) and $\mathrm{I}(\mathrm{CaL})$ in rabbit ventricular myocytes. Sci. Rep. 2019, 9, 20425. [CrossRef]

28. Chen, H.; Shen, J.; Li, H.; Zheng, X.; Kang, D.; Xu, Y.; Chen, C.; Guo, H.; Xie, L.; Wang, G.; et al. Ginsenoside Rb1 exerts neuroprotective effects through regulation of Lactobacillus helveticus abundance and GABA(A) receptor expression. J. Ginseng. Res. 2020, 44, 86-95. [CrossRef]

29. Ahmed, T.; Raza, S.H.; Maryam, A.; Setzer, W.N.; Braidy, N.; Nabavi, S.F.; de Oliveira, M.R.; Nabavi, S.M. Ginsenoside Rb1 as a neuroprotective agent: A review. Brain Res. Bull. 2016, 125, 30-43. [CrossRef]

30. Liu, X.; Chen, J.; Sun, N.; Li, N.; Zhang, Z.; Zheng, T.; Li, Z. Ginsenoside Rb1 ameliorates autophagy via the AMPK/mTOR pathway in renal tubular epithelial cells in vitro and in vivo. Int. J. Biol. Macromol. 2020, 163, 996-1009. [CrossRef]

31. Rajput, S.A.; Shaukat, A.; Rajput, I.R.; Kamboh, A.A.; Iqbal, Z.; Saeed, M.; Akhtar, R.W.; Shah, S.A.H.; Raza, M.A.; El Askary, A.; et al. Ginsenoside Rb1 prevents deoxynivalenol-induced immune injury via alleviating oxidative stress and apoptosis in mice. Ecotoxicol. Environ. Saf. 2021, 220, 112333. [CrossRef]

32. Shaukat, A.; Yang, C.; Yang, Y.; Guo, Y.F.; Jiang, K.; Guo, S.; Liu, J.; Zhang, T.; Zhao, G.; Ma, X.; et al. Ginsenoside Rb 1: A novel therapeutic agent in Staphylococcusaureus-induced Acute Lung Injury with special reference to Oxidative stress and Apoptosis. Microbial Pathog. 2020, 143, 104109. [CrossRef] [PubMed]

33. Akhtar, M.; Shaukat, A.; Zahoor, A.; Chen, Y.; Wang, Y.; Yang, M.; Umar, T.; Guo, M.; Deng, G. Hederacoside-C inhibition of Staphylococcus aureus-induced mastitis via TLR2 \& TLR4 and their downstream signaling NF-kB and MAPKs pathways in vivo and in vitro. Inflammation 2019, 43, 579-594.

34. Guo, J.; Wang, Y.; Jiang, P.; Yao, H.; Zhao, C.; Hu, X.; Cao, Y.; Zhang, N.; Fu, Y.; Shen, H. Sodium butyrate alleviates lipopolysaccharide-induced endometritis in mice through inhibiting inflammatory response. Microbial Pathog. 2019, 137, 103792. [CrossRef] [PubMed]

35. Jiang, K.; Yang, J.; Yang, C.; Zhang, T.; Shaukat, A.; Yang, X.; Dai, A.; Wu, H.; Deng, G. miR-148a suppresses inflammation in lipopolysaccharide-induced endometritis. J. Cell. Mol. Med. 2020, 24, 405-417. [CrossRef] [PubMed]

36. Umar, T.; Yin, B.; Umer, S.; Ma, X.; Jiang, K.; Umar, Z.; Akhtar, M.; Shaukat, A.; Deng, G. MicroRNA: Could It Play a Role in Bovine Endometritis? Inflammation 2021, 44, 1683-1695. [CrossRef] 
37. Zhou, M.; Yi, Y.; Hong, L. Oridonin Ameliorates Lipopolysaccharide-Induced Endometritis in Mice via Inhibition of the TLR4/NF-kBpathway. Inflammation 2019, 42, 81-90. [CrossRef]

38. Wu, H.; Jiang, K.; Yin, N.; Ma, X.; Zhao, G.; Qiu, C.; Deng, G. Thymol mitigates lipopolysaccharide-induced endometritis by regulating the TLR4-and ROS-mediated NF- $\mathrm{BB}$ signaling pathways. Oncotarget 2017, 8, 20042. [CrossRef]

39. Fu, K.; Lv, X.; Li, W.; Wang, Y.; Li, H.; Tian, W.; Cao, R. Berberine hydrochloride attenuates lipopolysaccharide-induced endometritis in mice by suppressing activation of NF-KB signal pathway. Int. Immunopharmacol. 2015, 24, 128-132. [CrossRef]

40. Shaukat, A.; Hanif, S.; Shaukat, I.; Shukat, R.; Rajput, S.A.; Jiang, K.; Akhtar, M.; Yang, Y.; Guo, S.; Shaukat, I. Upregulated-gene expression of pro-inflammatory cytokines, oxidative stress and apoptotic markers through inflammatory, oxidative and apoptosis mediated signaling pathways in bovine pneumonia. Microbial Pathog. 2021, 155, 104935. [CrossRef]

41. Akhtar, M.; Guo, S.; Guo, Y.-f.; Zahoor, A.; Shaukat, A.; Chen, Y.; Umar, T.; Deng, G.; Guo, M. Upregulated-gene expression of Pro-inflammatory cytokines (TNF- $\alpha$, IL-1 $\beta$ and IL-6) via TLRs following NF-kB and MAPKs in bovine mastitis. Acta Trop. 2020, 207, 105458. [CrossRef]

42. Zahoor, A.; Yang, Y.; Yang, C.; Akhtar, M.; Guo, Y.; Shaukat, A.; Guo, M.Y.; Deng, G. Gas6 negatively regulates the Staphylococcus aureus-induced inflammatory response via TLR signaling in the mouse mammary gland. J. Cell. Physiol. 2020, 235, 7081-7093. [CrossRef] [PubMed]

43. Akhtar, M.; Shaukat, A.; Zahoor, A.; Chen, Y.; Wang, Y.; Yang, M.; Umar, T.; Guo, M.; Deng, G. Anti-inflammatory effects of Hederacoside-C on Staphylococcus aureus induced inflammation via TLRs and their downstream signal pathway in vivo and in vitro. Microbial Pathog. 2019, 137, 103767. [CrossRef] [PubMed]

44. Wang, X.; Yuan, T.; Yin, N.; Ma, X.; Zhang, Z.; Zhu, Z.; Shaukat, A.; Deng, G. Luteoloside Protects the Uterus from Staphylococcus aureus-Induced Inflammation, Apoptosis, and Injury. Inflammation 2018, 41, 1702-1716. [CrossRef] [PubMed]

45. Akira, S.; Hirano, T.; Taga, T.; Kishimoto, T. Biology of multifunctional cytokines: IL 6 and related molecules (IL 1 and TNF). FASEB J. 1990, 4, 2860-2867. [CrossRef]

46. Dinarello, C.A. A clinical perspective of IL-1 $\beta$ as the gatekeeper of inflammation. Eur. J. Immunol. 2011, 41, 1203-1217. [CrossRef]

47. Chen, C.-Y.; Peng, W.-H.; Tsai, K.-D.; Hsu, S.-L. Luteolin suppresses inflammation-associated gene expression by blocking NF-кB and AP-1 activation pathway in mouse alveolar macrophages. Life Sci. 2007, 81, 1602-1614. [CrossRef] 